\title{
Acute Panmyelosis with Myelofibrosis
}

National Cancer Institute

\section{Source}

National Cancer Institute. Acute Panmyelosis with Myelofibrosis. NCI Thesaurus. Code C4344.

An acute myeloid leukemia characterized by bone marrow fibrosis without preexisting primary myelofibrosis. 